\title{
The Funny Current in Cardiac Non-Pacemaker Cells: Functional Role and Pharmacological Modulation
}

\author{
Laura Sartiani, Elisabetta Cerbai and Alessandro Mugelli \\ Department of Pharmacology, Center of Molecular Medicine, University of Florence
}

Italy

\section{Introduction}

In mammalians, heart rhythm originates in the sinoatrial node, a specialized region of the right atrium with defined anatomical and functional properties. The sinoatrial node acts as primary pacemaker in the heart owing to its unique ability to generate spontaneous action potentials at a rate faster than subsidiary pacemakers (the atrioventricular node and Purkinje fibers) (Vassalle, 1977). Propagation of action potentials from the sinoatrial node is first directed to the atria and then to the ventricles through a specialized conduction system that drives and coordinates the rhythmic contraction of heart chambers (Figure 1).

The pacemaker function of the sinoatrial node derives from a key electrogenic property, the diastolic depolarization phase or pacemaker phase of the action potential. It is a slow, positive increase in voltage across the cell membrane occurring between the end of one action potential and the beginning of the next; it causes the cell membrane to reach the threshold potential required to generate a subsequent action potential (DiFrancesco, 1991; DiFrancesco, 2010). The diastolic depolarization phase is absent in normal atrial and ventricular myocytes that rest at stable membrane potential values at the termination of the action potential.

Investigations aimed at elucidating the ionic mechanisms of pacemaking have proposed different candidates as major contributors responsible for the generation of the diastolic depolarization phase. At present, despite the issue is still a matter of debate, a wealth of information clearly agrees that two major mechanisms, membrane-associated ion currents and calcium release from sarcoplasmic reticulum, contribute to form a coordinated system that drives automaticity of normal cardiac pacemaker cells (Lakatta et al., 2010).

Among the membrane associated currents, the hyperpolarization-activated current or funny current $\left(\mathrm{I}_{\mathrm{f}}\right)$ is considered a major player in both generation of cardiac spontaneous activity and rate control (DiFrancesco, 1991; DiFrancesco, 2010). $\mathrm{I}_{\mathrm{f}}$ is an inward mixed-cation current carried by potassium and sodium, slowly activating on hyperpolarization at voltages comprising the diastolic depolarization phase of sinoatrial node cells $(-40 /-60 \mathrm{mV})$; for these reasons it was termed funny current. Accordingly, several loss-of-function mutations (DiFrancesco, 2010), as well as the down-regulation of constitutive subunits of f-channel in pacemaker cells (Zicha et al., 2005) have been demonstrated to cause sinus node dysfunction and rhythm disturbances. 


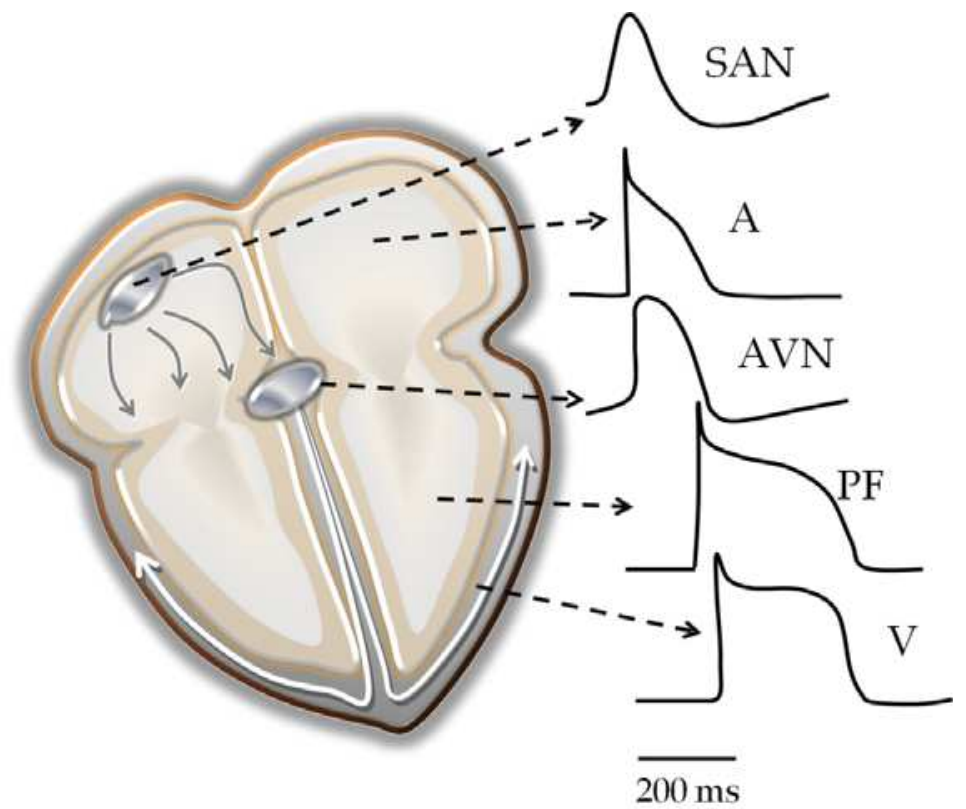

Representative action potentials from different regions of the heart. Displacement in time reflects the temporal sequence of impulse propagation through the heart. Abbreviations: SAN, sinoatrial node; A, atrium; AVN, atrioventricular node; PF, Purkinje fibers; V, ventricle; ms, milliseconds.

Fig. 1. Action potential profiles and propagation in the human heart.

Despite funny current expression has long been considered restricted to the sinus node and other regions of the conducting system, i.e. those cells possessing a diastolic depolarization phase, functional and molecular data collected over the last fifteen years have identified funny channels in non-pacemaker cardiomyocytes of the heart, namely in atrial and ventricular myocytes (Cerbai \& Mugelli, 2006; Biel et al., 2009). In this cells, the increased expression of funny current occurring in cardiac diseases (see below), such as in hypertrophy and failure, has been suggested to contribute to ectopic beat formation and enhanced electrical activity.

\section{Molecular properties and distribution of funny channels in the normal heart}

Funny channel constitutive subunits were cloned starting from the late 1990s (Ludwig et al., 1999; Moosmang et al., 2001; Biel et al., 2009). They belong to the superfamily of the voltagedependent potassium and cyclic nucleotide regulated channels and represent a gene family comprising four members, termed Hyperpolarization-activated Cyclic Nucleotide-gated (HCN1-4) channels.

The four different subunits assemble in homo-tetramers with distinct biophysical properties, but there is evidence in vivo that different subunits may combine in the same protein complex forming hetero-tetramers with specific kinetic and modulatory properties (Figure 2) (Biel et al., 2009). HCN isoforms share a highly conserved transmembrane core sequence, while their $\mathrm{N}$ and $\mathrm{C}$ termini vary considerably in terms of length and sequence homology. 
In the membrane, $\mathrm{HCN}$ tetramers form pore-loop channels that arrange around a centrally located pore. Each subunit consists of six $\alpha$-helical transmembrane segments that include the core sequence, responsible for channel gating properties and ion selectivity, and the intracellular cytosolic C-terminal domain, responsible for channel modulation by cyclic nucleotides.

In the adult heart, a wealth of information documented a robust expression of HCN1, HCN2 and HCN4 isoforms, while very low levels of HCN3 are present (Cerbai \& Mugelli, 2006; Biel et al., 2009). In general, there is a strong variation of isoform quantity according to cardiac region, since expression levels of total $\mathrm{HCN}$ channels are low in normal atrial and ventricular muscle compared with those detected in the sinoatrial node region and in the conduction system. Moreover, there is also a clear variation of isoform predominance according to species. In the adult sinoatrial node of humans, rabbit, guinea pig, mouse and dog, HCN4 is the dominant isoform, accounting for the majority of the total HCN transcripts. By contrast HCN2 isoform predominates in rat sinoatrial node. The remaining fraction is mainly represented by HCN2 isoform in humans and mouse and HCN1 isoform

A
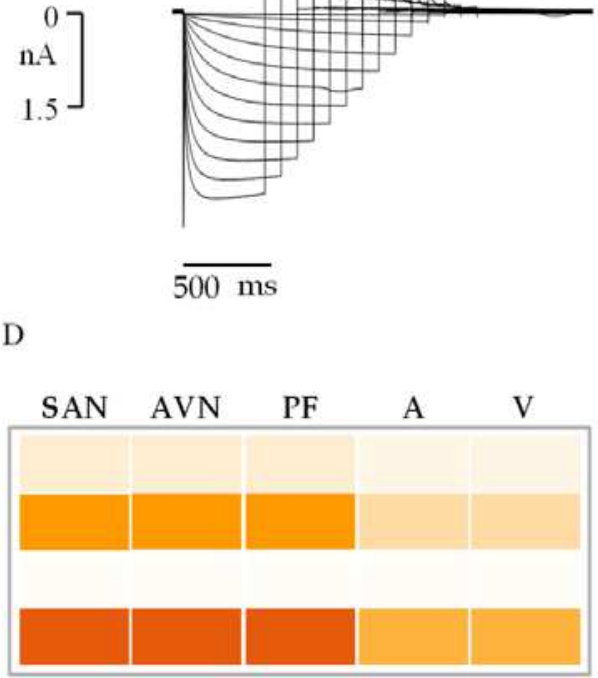

B

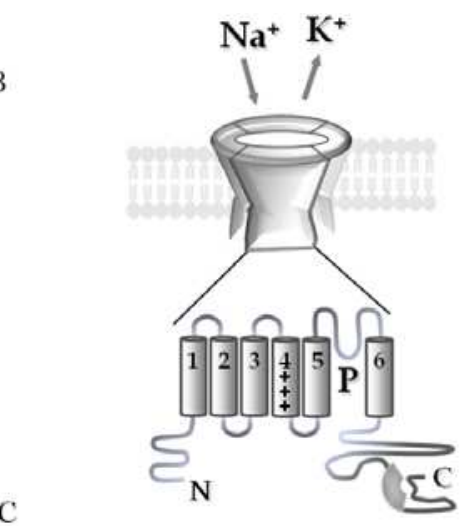

$\mathrm{C}$

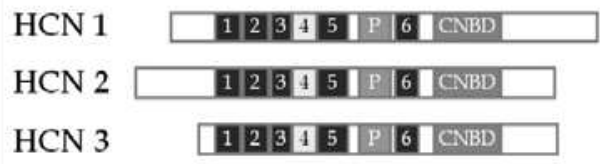

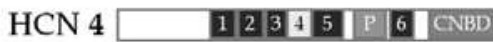

A: Representative family of $\mathrm{I}_{\mathrm{f}}$ traces elicited by hyperpolarizing steps recorded in a sinoatrial node cell isolated from guinea-pig. B: Tetrameric structure of $\mathrm{HCN}$ channels: each monomer is formed by six trans-membrane segments (1-6), a pore loop $(\mathrm{P})$ between segments 5 and 6, a voltage sensor motif in segment 4 and a cyclic-nucleotide-binding domain (CNBD) in the C-terminal region; C: HCN family formed by four isoforms termed HCN1-4. D: HCN isoform distribution in different regions of the human heart; intensity of colour is an index of isoform expression. Abbreviations: $\mathrm{nA}$, nanoAmpere; ms, milliseconds; SAN, sinoatrial node; A, atrium; AVN, atrioventricular node; PF, Purkinje fibers; V, ventricle.

Fig. 2. Properties, topology and distribution of funny-channels in the heart. 
in rabbit. HCN4 is the most abundant isoform in human atrioventricular node and Purkinje fibers, while HCN2 is the most largely expressed isoform in canine Purkinje fibers. Rabbit Purkinje fibers exhibit little $\mathrm{I}_{\mathrm{f}}$ which is associated to low levels of HCN4 and HCN1 expressed in equal amount. In the conduction system no expression or only very low expression levels have been reported for HCN3 isoform. Despite the high interspecies variability shown by funny channels in the heart, a number of data point to HCN4 and $\mathrm{HCN} 2$ as the most represented isoforms in atrial and ventricular muscle of the majority of mammals, including humans. In these regions low levels of HCN1 and HCN3 have also been detected.

\section{Expression and properties of funny channels in ventricular cardiomyocytes}

The study of the electrophysiological mechanisms of arrhythmias has characterized the activity of our research group since long time (Vassalle \& Mugelli, 1981). In the early 1990s, we were actively studying the electrophysiological alterations occurring in the hypertrophied heart of old spontaneously hypertensive rats. The goal was to get insight into the electrophysiological mechanisms underlying the enhanced arrhythmogenesis occurring in cardiac hypertrophy. We found that action potentials recorded in left ventricular papillary muscles isolated from hypertrophied hearts showed several electrophysiological alterations including an unusual diastolic depolarization phase, which was not present in preparations excised from normal hearts (Barbieri et al., 1994). Interestingly enough, in the same experimental model we documented that the slope of this sort of diastolic depolarization was clearly enhanced upon catecholamine stimulation, similarly to what previously described for the oscillatory current in Purkinje fibers (Vassalle \& Mugelli, 1981). We were able to demonstrate that a relevant contribution to the diastolic depolarization phase present in hypertrophied hearts was due to the occurrence of an atypical $\mathrm{I}_{\mathrm{f}}$ current that was functionally expressed in ventricular hypertrophic cardiomyoctes, but not in normal cardiomyoctes (Cerbai et al., 1994). Later on we demonstrated that $I_{f}$ density in the hypertrophied rat hearts was linearly related to the severity of myocardial hypertrophy (Cerbai et al., 1996).

$\mathrm{I}_{\mathrm{f}}$ recorded in ventricular rat cardiomyocytes showed electrophysiological properties, responsiveness to autonomic transmitters and sensitivity to pharmacological blockade similar to those observed for $\mathrm{I}_{\mathrm{f}}$ expressed in the sinoatrial node (Cerbai et al., 1996). In particular, voltage-dependence, kinetics of activation and ionic selectivity were qualitatively similar to those retrieved in cardiac pacemaker cells. However, threshold of current activation differed substantially, being much more negative (about $-70 \mathrm{mV}$ ) than that reported for sinoatrial node cells $(-40 \mathrm{mV})$. On the basis of present knowledge on diverse $\mathrm{HCN}$ isoform distribution in the heart (see previous paragraph), the observed difference on $\mathrm{I}_{\mathrm{f}}$ current activation likely reflects a diverse composition of $\mathrm{HCN}$ isoforms contributing to channel complex in the sinoatrial node and in the ventricular tissue. In addition to this, membrane sub-localization with interacting proteins, e.g. caveolin-3, may also contribute to differences in channel voltage activation (Barbuti et al., 2004; Barbuti et al., 2007). Despite the observed properties of funny current in the ventricular cardiomyocytes, a contribution to the diastolic phase of ventricular action potential is possible, since membrane resting potential is also more negative in ventricular cells than in sinoatrial node cells. 
Action of catecholamines on the funny current expressed in ventricular myocytes was proved to closely resemble that reported for myocytes from sinoatrial node (Cerbai et al., 1999). In fact, stimulation of $\beta$-adrenoceptors shifts the $I_{f}$ activation curve toward less negative values, with no change in the amplitude of the maximal specific conductance of the current. According to early observations (DiFrancesco \& Tortora, 1991; DiFrancesco, 2010), this effect results from a direct binding and positive modulation of channel function exerted by 3'-5'-cyclic adenosine monophosphate nucleotide, whose intracellular levels are greatly enhanced by $\beta$-adrenoceptors stimulation. The effect of catecholamines on the funny current expressed in ventricular myocytes is in accordance with the diverse sensitivity to cyclic nucleotide reported for the different channel isoforms. Indeed, HCN2 and HCN4, the most abundant isoforms in the ventricle, are largely modulated by cyclic nucleotides, while $\mathrm{HCN} 1$ and $\mathrm{HCN} 3$, which are not present or have a very low expression in the ventricle, are weakly affected (Biel et al., 2009).

Subsequent experimental evidence led to the demonstration that $I_{f}$ over-expression in ventricular cells occurred in other models of cardiac hypertrophy (Stilli et al., 2001) or following myocardial infarction (Sartiani et al., 2006): this suggests the involvement of a common mechanism controlling funny channels expression in cardiac diseases, such as ischemia and pathological hypertrophy. Finally and most importantly, a similar If gain-offunction was reported in human cardiac ventricular myocytes isolated from explanted

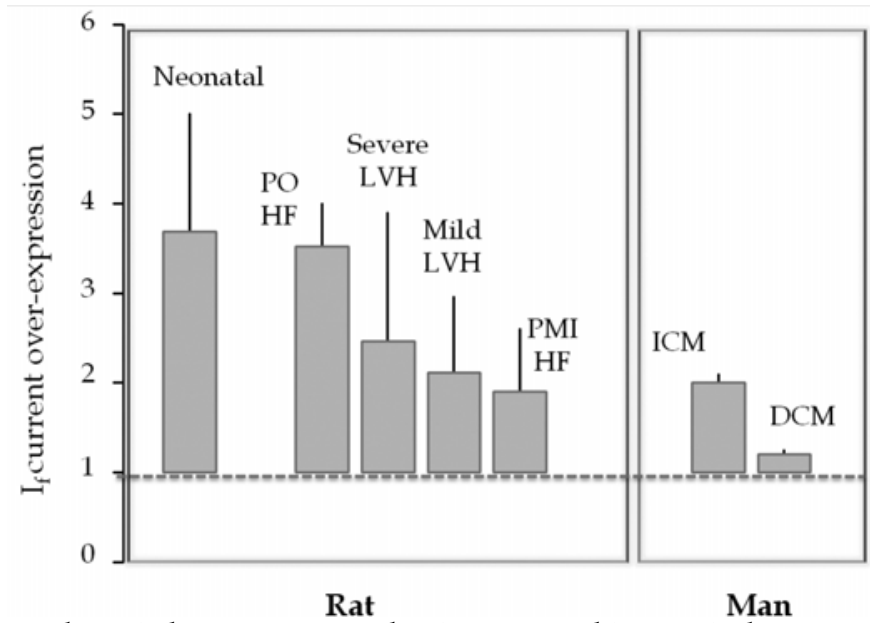

Columns represent the ratio between current density measured in ventricular myocytes from diseased hearts, and respective control; bars are confidence intervals (95\%). In newborn rats, values measured at 2 weeks are compared to those at 2 days after birth. LVH-mild, LVH-severe: relative increase of If current in rats with mild or severe left ventricular hypertrophy caused by aortic banding or long-lasting pressure overload, respectively. PO-HF, PMI-HF: relative increase of $I_{f}$ in rats with overt heart failure, resulting from uncompensated hypertrophy due to pressure-overload or following a myocardial infarction due to coronary ligation, respectively. DCM, ICM: relative increase of $\mathrm{I}_{\mathrm{f}}$ in patients undergoing cardiac transplantation for terminal dilated or ischemic cardiomyopathy, respectively. For all conditions, the relative increase of If density was statistically significant versus controls, that is, normotensive rats, sham-operated rats, or normal donor hearts not transplanted for technical reasons, with the exception of DCM patients.

Fig. 3. $\mathrm{I}_{\mathrm{f}}$ over-expression in cardiomyophaties and during cardiac development. 
hearts (Cerbai, 1997; Hoppe, 1998). Interestingly enough, in human ventricular myocytes functional over-expression of $\mathrm{I}_{\mathrm{f}}$ appeared to be related to the etiology of the disease, since current density is higher in ischemic than in dilated cardiomyopathy (Figure 3) (Cerbai et al., 2001).

Overall, these observations suggested that in the setting of structural and functional myocardial remodeling induced by pathology, If gain-of-function may contribute to the increased propensity for arrhythmias, a phenomenon documented both in patients and in experimental animal models. In this context, an over-activation of adrenergic system may increase the arrhythmogenic role played by $\mathrm{I}_{\mathrm{f}}$ channels.

In the human healthy ventricle, distribution of $\mathrm{HCN}$ isoforms shows a robust expression of HCN2 and HCN4 isoforms. In accordance with the electrophysiological data showing a larger amplitude of funny current in failing human ventricular myocytes, levels of HCN4 and HCN2 isoforms are greatly enhanced both at transcriptional (Figure 4) and protein

A

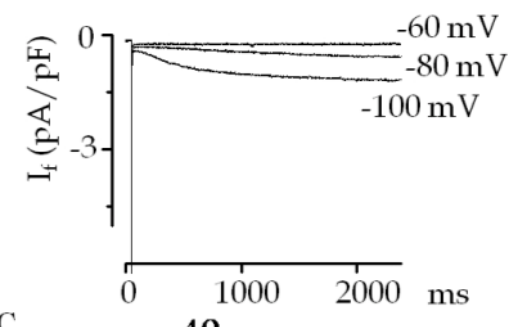

$\mathrm{C}$

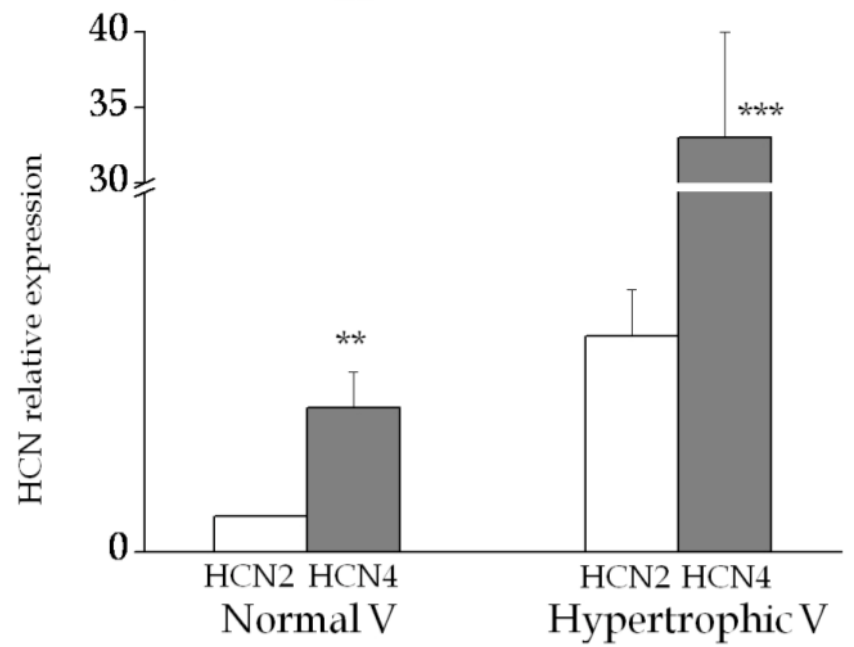

B

\section{Hypertrophic VCM}

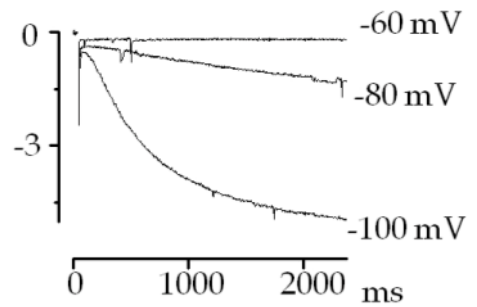

Representative traces of $\mathrm{I}_{\mathrm{f}}$ recorded in a normal (A) and a hypertrophic (B) ventricular cardiomyocyte (VCM) isolated from human hearts. C: Quantification of HCN2 and HCN4 mRNA relative to the reference gene Glyceraldehyde-3-Phosphate Dehydrogenase, in human normal and hypertrophic ventricle (Normal $\mathrm{V}$ and Hypertrophic $\mathrm{V}$, respectively). Abbreviations: $\mathrm{pA}$, picoAmpere; $\mathrm{pF}$, picoFarad; $\mathrm{mV}$, milliVolts; ms, milliseconds.

Fig. 4. Functional and molecular properties of funny-channel in the human ventricle. 
levels (Stillitano et al., 2008). A similar increase of HCN4 and HCN2 has been also documented in animal models of cardiac infarction (Suffredini et al., 2009) and hypertrophy (Fernandez-Velasco et al., 2003) and strongly suggests that cardiac pathology affects funny channel expression in ventricular myocytes. This phenomenon could modify the electrophysiological properties of cardiomyocytes, raising the tendency of the ventricular muscle to develop ectopic action potentials.

In summary, funny channel over-expression in non pacemaker ventricular cells, is a marker of remodeling induced by pathology and is likely to predispose cells to electrical instability. Funny channel over-expression, if associated with particular conditions documented in heart failure -namely a reduced expression of inwardly rectifying potassium current and elevated $\beta$-adrenergic stimulation- might contribute to trigger fatal arrhythmias.

\section{Expression and properties of funny channels in atrial cardiomyocytes}

Existence of funny current in human atrial appendage fibers was documented by Carmeliet on 1984 (Carmeliet, 1984), who first hypothesized the inherent potentiality of this current in human atrial tissue to develop spontaneous activity. The following experimental evidence allowed a thorough description of the properties of the funny current expressed in isolated human atrial myocytes obtained from atrial appendages excised during corrective cardiosurgery (Heidbuchel et al., 1987; Thuringer et al., 1992; Porciatti et al., 1997). On the basis of a number of experimental data it was documented that the funny current in atrial myocytes has a large variability in terms of amplitude and shows an activation voltage more negative than the atrial diastolic potential. These observations led to the general conclusion that the contribution of funny current to atrial electrogenesis is likely to be negligible in normal conditions. Despite this, a clear-cut diastolic depolarization phase is observed in human atrial myocytes, provided that integrity of the intracellular milieu is preserved using the perforated patch technique (Cerbai \& Mugelli, 2006).

The physiological role of funny current in normal atrial tissue is still a matter of investigation; however, a contribution to atrial electrogenesis has been suggested in pathological conditions and/or following the activation of specific neurohumoral signals that may amplify current density at physiological potentials (Opthof, 1998; Michels et al., 2005). Among the potentially relevant signals, two are peculiar of the human atrium and have been investigated in our laboratory: serotonin and atrial natriuretic peptide. Serotonin subtype-4 receptors are typically expressed in the human atrium (Kaumann, 1991), where at least four different splicing-variant isoforms have been identified (Blondel et al., 1998; Bach et al., 2001; Lezoualc'h et al., 2007). Serotonin subtype-4 receptors are coupled to Gs proteins that upon stimulation increase intracellular levels of 3'-5'-cyclic adenosine monophosphate (Pindon et al., 2002) that positively modulates the funny current. Atrial natriuretic peptide is synthesized and stored as pro-hormone in granules localized in human atrial myocytes (Venugopal, 2001). Upon atrial distension, the peptide is released and interacts with specific receptors, namely natriuretic peptides receptor A and B. These are membrane-associated receptors coupled to guanylyl cyclase activity that increases intracellular 3'-5'-cyclic guanosine monophosphate nucleotide, which similarly to the adenosine cyclic nucleotide, binds to funny channels and increases the current. Accordingly, both serotonin and atrial natriuretic peptide proved to increase $\mathrm{I}_{\mathrm{f}}$ current in human atrial myocytes (Pino et al., 1998; Lonardo et al., 2004). The effect is concentration-dependent and shows an affinity constant (Kd) quite similar to the physiological concentrations of serotonin and atrial natriuretic peptide likely reached upon adequate stimuli, i.e. local release during platelet aggregation 
or cell stretching, respectively. On the whole, these findings suggest that stimuli most likely involved in atrial arrhythmias are able to cause a gain of function of funny current in human atrial myocytes. Again this phenomenon could influence cell excitability and predispose to the occurrence of atrial arrhythmias.

\section{Funny channel over-expression in cardiomyocytes is a marker of regression toward an immature phenotype}

The understanding of the mechanisms and factors responsible for the functional overexpression of funny current in cardiac diseases is of great importance. Cardiac remodeling is a well defined phenomenon consisting of modifications in the structural and functional properties of the cardiac tissue (Swynghedauw, 1999), which occurs in several cardiac diseases. We hypothesized that the over-expression of funny channels in the diseased ventricle is likely part of the fetal/embryonic gene pattern that is known to be re-expressed in the heart during remodeling.

Ventricular cardiomyocytes are physiologically quiescent in the adult stage, but their action potentials exhibit a clear-cut diastolic depolarization phase in the immature stage. This property was associated with a robust expression of funny current in both rat fetal and neonatal cardiomyotes (Cerbai et al., 1999; Robinson et al., 1997; Sartiani et al., 2010). Further experimental evidences demonstrated that funny current occurrence and density are maximal in the first week of post-natal life and progressively decrease during maturation, reaching a low steady-state levels at one month of age. A minority of myocytes isolated from the hearts of adult rats express $\mathrm{I}_{\mathrm{f}}$, which, when present, was of small amplitude.

In accordance with data reported in the fetal mouse (Yasui et al., 2001; Mommersteeg et al., 2007; Schweizer et al., 2009), expression analysis in the rat documented that both HCN4 and $\mathrm{HCN} 2$ isoforms account for the majority of total HCN transcript in the neonatal ventricle, while HCN1 and HCN3 isoforms are not expressed at detectable levels (Sartiani et al., 2010). Interestingly, HCN4 is down-regulated during rat heart maturation, but in association with HCN2 it undergoes a clear-cut up-regulation after cardiac infarction (Suffredini et al., 2009). This observation confirms the hypothesis that transcriptional regulation in the remodeled heart involves funny channel isoforms typical of the immature ventricle, which are modulated as part of a panel of other key fetal/immature genes.

At variance with experimental animal models, obvious difficulties are encountered to get information on developmental changes of funny current in humans. A useful experimental model to overcome this difficulty is represented by human embryonic stem cells induced to differentiate toward the cardiac phenotype (Sartiani et al., 2007; Bettiol et al., 2007). This model is reported to recapitulate native cardiac embryogenesis and maturation, thus representing a useful tool to study early human cardiac development and growth. Using this model we documented that the funny current is present since the undifferentiated state, where its functional role in association with other ion channels, e.g. delayed rectifier potassium channels, still remains to be elucidated. After induction of cardiac differentiation, funny channels continue to be functionally present both in the early and late stages of cardiac differentiation. During this process the differentiating human cardiomyocytes undergo a number of key changes in terms of excitable properties and molecular phenotype that include modifications of funny channels. In fact, kinetics of $I_{f}$ activation are markedly slowed-down in late-stage cardiomyocytes compared to the early ones and undifferentiated cells. Changes in kinetics during differentiation and maturation turned out to result from 
modifications of isoforms contributing to channel complex. In fact, when heterologously reexpressed as homomeric channels, HCN1 shows rapid activation kinetics (tens of milliseconds), whereas $\mathrm{HCN} 2$ and $\mathrm{HCN} 4$ activate in hundreds of milliseconds. In accordance with functional data, expression analysis of $\mathrm{HCN}$ isoform on differentiating cardiomyocytes showed that HCN1 isoform, which has the fastest activation kinetics, is largely expressed in undifferentiated cells and in early-stage cardiomyocytes, but is significantly reduced during maturation. The slower HCN2 isoform is expressed homogeneously throughout the differentiation process while $\mathrm{HCN} 4$ results to be dramatically down-regulated. On the whole, these observations suggest that, in accordance with data retrieved in native cardiac tissue (Figure 4), in human cardiomyocytes differentiated from embryonic stem cells HCN2 and HCN4 account for the majority of total HCN transcript and likely contribute to funny channel complex and properties.

In conclusion, funny channels are abundantly expressed in human cardiomyocytes differentiated from embryonic stem cells at all stages of differentiation and thus they represent a marker of immature cardiac phenotype in mammals. During maturation funny channels undergo modifications in terms of current properties and isoform composition. As previously suggested for the rat heart, changes in HCN isoform expression (downregulation of HCN4) are opposite to those observed in heart hypertrophy and failure (upregulation of $\mathrm{HCN} 4$ and $\mathrm{HCN} 2$ ) where the functional re-expression of funny current likely represent a regression toward an immature cardiac phenotype.

\section{Pharmacological modulation of funny channels in the heart}

In heart hypertrophy and failure, a complex signaling network contributes to initiate and exacerbate cardiac functional and molecular remodeling. Over the last years, a growing number of experimental evidence has been accumulating and documented the involvement of diverse factors in the patophysiology of the phenomenon. To date only some signalling pathways have been identified and extensively studied. Among the best documented, experimental and clinical evidence points to a central role for the increased levels of systemic and locally released hormonal factors, including norepinephrine, angiotensin II, endothelin I, aldosterone and cytokines (De Mello, 2004; Swynghedauw, 1999).

On the basis of our observation that funny channels are over-expressed in the diseased ventricular tissue, we assessed the involvement of the renin-angiotensin system, that is activated in cardiac hypertrophy/failure, in the regulation of funny channels (Figure 5). Using an experimental model of cardiac hypertrophy, the old spontaneously hypertensive rat, we tested the effect of type- 1 angiotensin II receptor antagonists, losartan or irbesartan, orally administered for 8-weeks. The treatment proved to prevent the development of several electrophysiological alterations associated with cardiac hypertrophy, i.e. the action potential prolongation, the transient outward potassium current down-regulation and also the over-expression of funny current (Cerbai et al., 2000; Cerbai et al., 2003).

Recent clinical trials documented that reduction of heart rate with pacing (Rao et al., 2007) or selective bradycardic agents (Swedberg et al., 2010; Böhm et al., 2010) is associated to improved clinical outcomes in heart failure. Studies were performed in animal models to assess whether selective pharmacological intervention able to control heart rate were able to revert and/or ameliorate functional remodeling of ventricular tissue in cardiac diseases. In a rat model of myocardial infarction it was documented that reduction of heart rate with a 


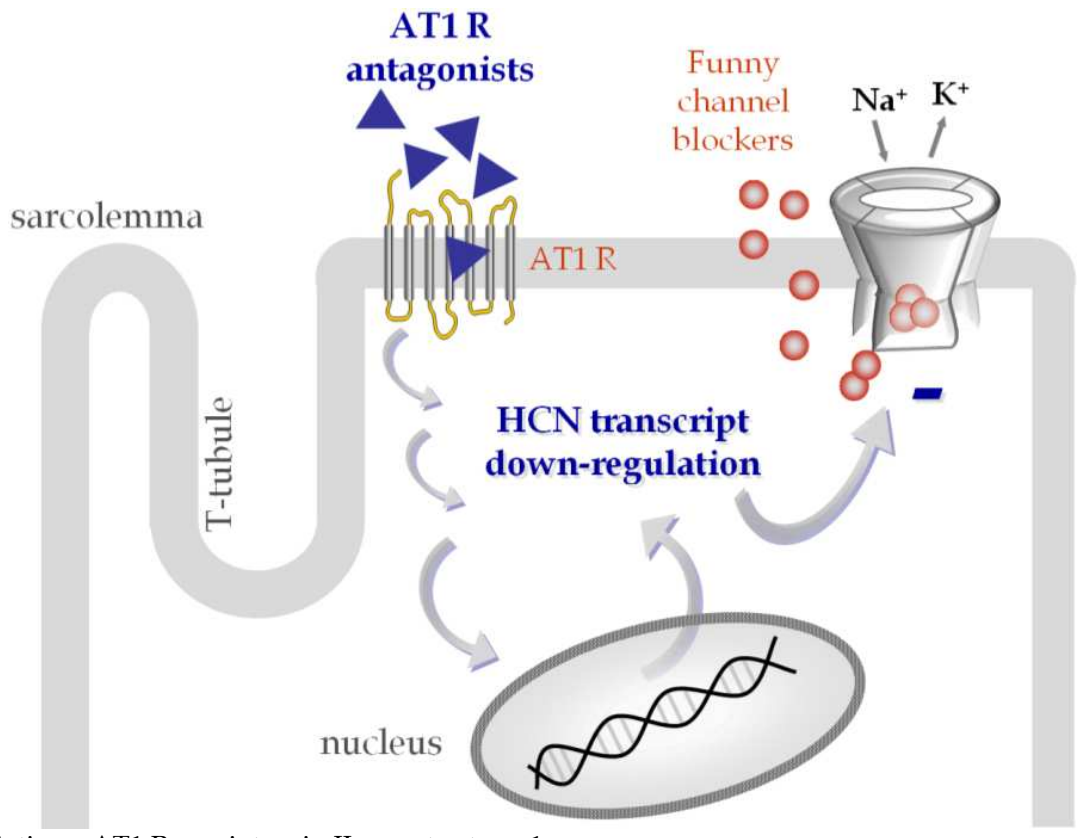

Abbreviations: AT1 R: angiotensin II receptor type 1.

Fig. 5. Schematic representation of pharmacological interventions able to modulate funny channel expression and/or function in cardiomyocytes.

selective bradycardic agent (ivabradine, see below for further details) is able to improve maximal myocardial perfusion and coronary reserve (Dedkov et al., 2007). On the basis of this evidence, we tested whether heart rate reduction with ivabradine in post-infarcted rats could counteract the electrophysiological remodeling of ventricular myocytes. Preliminary results proved that the treatment was able to ameliorate cardiac function as well as ion channels alterations, in particular the down-regulation of transient outward potassium current and the over-expression funny channels occurring in post-infarcted animals (Suffredini et al., 2009; Ceconi et al., 2007). At present, the mechanism(s) responsible for the reduction/reversion of ventricular functional remodeling with heart rate slowing drugs remains unknown and further investigations are necessary.

On the whole, over-expression of funny channels in ventricular cardiomyocytes is promoted by hypertrophic factors whose levels are increased during cardiac hypertrophy and failure. Over-expression of funny channels is inhibited by drugs that revert or prevent many of the electrophysiological alterations described in the remodeled cardiac myocytes.

In the last years, we have explored the pharmacological strategy aimed to modulate directly the cardiac funny channels, identifying novel molecules that act as direct channel blockers. The interest in funny channels direct modulators has emerged due to the approval of ivabradine (a prototype blocker of funny channel with selective bradycardic properties) for the treatment of stable angina pectoris. Our experimental approach took advantage of classical medicinal chemistry and electrophysiology and aimed to identify novel derivatives, structurally related to zatebradine (Romanelli et al., 2005), a different prototype blocker of 
funny channels, whose clinical trials were stopped due to adverse side effects. Moreover, since the most serious side effects of zatebradine are due to unselective blockade of the HCN isoforms present in tissues different from the heart, i.e. retinal rods and nervous system, one additional aim was to develop compounds able to discriminate among the HCN channel isoforms. Our recent results (Melchiorre et al., 2010) have uncovered diverse structural requirements necessary to provide derivative selectivity for the diverse $\mathrm{HCN}$ isoforms, which suggest a potential interest of these compounds as novel selective bradycardic agents. Investigations are currently characterizing the pharmacological profile of these novel funny channel blockers especially looking at their isoform selectivity.

\section{Summary and conclusion}

After their first discovery in the sinoatrial node, funny channels have been identified as key physiological regulators of pacemaker function in the heart. Subsequent studies have documented their expression in the atrial and ventricular muscles, where diverse pathologic conditions, such as cardiac hypertrophy and failure, cause their functional enhancement. This observation and the identification of different signaling pathways able to promote their function in the atria and ventricles has led to the suggestion that the funny current in non pacemaker cardiomyocytes may influence membrane excitability and predispose to the occurrence of arrhythmias. However, this hypothesis remains unproved in both experimental and clinical settings. The recent SHIFT study (Swedberg et al., 2010; Böhm et al., 2010) showed that ivabradine improves clinical outcomes in chronic heart failure, pointing to the reduction of heart rate as fundamental mechanism of drug action. However, the accompanying editorial (Teerlink, 2010) hypothesized that other mechanisms such us blockade of funny channels in the ventricle may contribute to the beneficial effects of ivabradine. Despite the progresses made, numerous key questions still remains unanswered and deserve a thorough investigation in the future. Among the most important, some of the unknown issues relate to:

i. the relevance and the specific role of funny channels in non pacemaker cells in different cardiac diseases.

1. the factors and signalling pathways controlling the expression, the cellular processing, and the sub-cellular compartmentation of funny channels in the normal and diseased heart.

2. the identifications of proteins and/or other (bio)molecules able to interact and modulate funny channels function in physiological and pathological conditions.

\section{Acknowledgments}

This work was supported by grants from Ministero dell'Istruzione, dell'Universita` e della Ricerca, Rome (Programmi di Ricerca di Interesse Nazionale 2008838SN9) and from European Union (STREP Project "NORMACOR", 6th European Framework Program, contract LSH M/CT/2006/018676).

\section{References}

Bach, T.; Syversveen, T.; Kvingedal, A.M.; Krobert, K.A.; Brattelid, T.; Kaumann, A.J. \& Levy, F.O. (2001). 5HT4(a) and 5-HT4(b) receptors have nearly identical 
pharmacology and are both expressed in human atrium and ventricle. NaunynSchmiedeberg's archives of pharmacology, 363, 146-160, pISSN: 0028-1298.

Barbieri, M.; Varani, K.; Cerbai, E.; Guerra, L.; Li, Q.; Borea, P.A. \& Mugelli, A. (1994). Electrophysiological basis for the enhanced cardiac arrhythmogenic effect of isoprenaline in aged spontaneously hypertensive rats. Journal of Molecular and Cellular Cardiology, 26, 7, 849-860, pISSN: 0022-2828.

Barbuti, A.; Gravante, B.; Riolfo, M.; Milanesi, R.; Terragni, B. and DiFrancesco, D. (2004). Localization of pacemaker channels in lipid rafts regulates channel kinetics. Circulation Research, 94, 10, 1325-1331, pISSN: 0009-7330.

Barbuti, A.; Terragni, B.; Brioschi, C. \& DiFrancesco, D. (2007). Localization of f-channels to caveolae mediates specific beta2-adrenergic receptor modulation of rate in sinoatrial myocytes. Journal of Molecular and Cellular Cardiology, 42, 1, 71-78, pISSN: 0022-2828.

Bettiol, E.; Sartiani, L.; Chicha, L.; Krause, K.H.; Cerbai, E. \& Jaconi, M.E. (2007). Fetal bovine serum enables cardiac differentiation of human embryonic stem cells. Differentiation; research in biological diversity, 75, 8, 669-681, pISSN: 0301 $-4681$.

Biel, M.; Wahl-Schott, C.; Michalakis, S. \& Zong, X. (2009). Hyperpolarization-activated cation channels: from genes to function. Physiological Reviews, 89, 3, 847-885, pISSN: 0031-9333.

Blondel, O.; Gastineau, M.; Dahmoune, Y.; Langlois, M. \& Fischmeister, R. (1998). Cloning, expression, and pharmacology of four human 5-hydroxytryptamine 4 receptor isoforms produced by alternative splicing in the carboxyl terminus. Journal of Neurochemistry, 70, 2252-2261, pISSN: 0022-3042.

Böhm, M.; Swedberg, K.; Komajda, M.; Borer, J.S.; Ford, I.; Dubost-Brama, A.; Lerebours, G.; Tavazzi, L.; SHIFT Investigators. (2010) Heart rate as a risk factor in chronic heart failure (SHIFT): the association between heart rate and outcomes in a randomised placebo-controlled trial. Lancet, 376 (9744), 886-94, pISSN: 0140-6736.

Carmeliet, E. (1984). Existence of pacemaker current $\mathrm{I}_{\mathrm{f}}$ in human atrial appendage fibres. The Journal of physiology, 357, 125P, abstract, pISSN: 0022-3751.

Ceconi, C.; Comini, L.; Suffredini, E.; Cerbai, E.; Ferrari, R.; Bouly, M. \& Mugelli, A. (2007). Structural and electrophysiological effects on cardiac remodeling by ivabradine. European heart journal supplements: journal of the European Society of Cardiology, 28, 42, abstract, ISSN: 1520-765X.

Cerbai, E. \& Mugelli, A. (2006). I(f) in non-pacemaker cells: role and pharmacological implications. Pharmacological research:the official journal of the Italian Pharmacological Society, 53, 5, 416-423, pISSN: 1043-6618.

Cerbai, E.; Pino, R.; Rodriguez, M.L. \& Mugelli, A. (1999). Modulation of the pacemaker current $\mathrm{I}_{\mathrm{f}}$ by beta-adrenoceptor subtypes in ventricular myocytes isolated from hypertensive and normotensive rats. Cardiovascular Research, 42, 1, 121-129, pISSN: 0008-6363.

Cerbai, E.; Barbieri, M. \& Mugelli, A. (1994). Characterization of the hyperpolarizationactivated current, $\mathrm{I}_{\mathrm{f}}$, in ventricular myocytes isolated from hypertensive rats. The Journal of physiology, 481, 585-591, pISSN: 0022-3751.

Cerbai, E.; Barbieri, M. \& Mugelli, A. (1996). Occurrence and properties of the hyperpolarization-activated current $I_{f}$ in ventricular myocytes from 
normotensive and hypertensive rats during aging. Circulation, 94, 1674-1681, pISSN: 0009-7322.

Cerbai, E.; Crucitti, A.; Sartiani, L.; De Paoli, P.; Pino, R., Rodriguez, M.L.; Gensini, G. \& Mugelli, A. (2000). Long-term treatment of spontaneously hypertensive rats with losartan and electrophysiological remodeling of cardiac myocytes. Cardiovascular Research, 45, 2, 388-396, pISSN: 0008-6363.

Cerbai, E.; De Paoli, P.; Sartiani, L.; Lonardo, G. \& Mugelli, A. (2003). Treatment with irbesartan counteracts the functional remodeling of ventricular myocytes from hypertensive rats. Journal of Cardiovascular Pharmacology, 41, 5, 804-812, pISSN: 01602446.

Cerbai, E.; Pino, R.; Porciatti, F.; Sani, G.; Toscano, M.; Maccherini, M.; Giunti, G. \& Mugelli, A. (1997). Characterization of the hyperpolarization-activated current, $I_{f}$, in ventricular myocytes from human failing heart. Circulation, 95, 568-571, pISSN: 0009-7322.

Cerbai, E.; Pino, R.; Sartiani, L. \& Mugelli, A. (1999). Influence of postnatal development on $\mathrm{I}_{\mathrm{f}}$ occurrence and properties in neonatal rat ventricular myocytes. Cardiovascular Research, 42, 416-423, pISSN: 0008-6363.

Cerbai, E.; Sartiani, L.; De Paoli, P.; Pino, R.; Maccherini, M.; Bizzarri, F.; DiCiolla, F.; Davoli, G.; Sani, G. \& Mugelli, A. (2001). The properties of the pacemaker current $I_{f}$ in human ventricular myocytes are modulated by cardiac disease. Journal of Molecular and Cellular Cardiology, 33, 441-448, pISSN: 0022-2828.

De Mello, W.C. (2004). Heart failure: how important is cellular sequestration? The role of the renin-angiotensin-aldosterone system. Journal of Molecular and Cellular Cardiology, 37, 2, 431-438, pISSN: 0022-2828.

Dedkov, E. I.; Zheng, W.; Christensen, L. P.; Weiss, R. M.; Mahlberg-Gaudin, F. \& Tomanek, R. J. (2007). Preservation of coronary reserve by ivabradine-induced reduction in heart rate in infarcted rats is associated with decrease in perivascular collagen. American Journal of Physiology. Heart and Circulatory Physiology, 293, 1, H590-H598, pISSN: 0363-6135.

DiFrancesco, D. \& Tortora, P. (1991). Direct activation of cardiac pacemaker channels by intracellular cyclic AMP. Nature, 351, 6322, 145-147, pISSN: 0028-0836.

DiFrancesco, D. (1991). The contribution of the 'pacemaker' current $\left(\mathrm{I}_{\mathrm{f}}\right)$ to generation of spontaneous activity in rabbit sino-atrial node myocytes. The Journal of Physiology, 434, 23-40, pISSN: 0022-3751.

DiFrancesco, D. (2010). The role of the funny current in pacemaker activity. Circulation Research, 106, 3, 434-446, pISSN: 0009-7330.

Fernandez-Velasco, M.; Goren, N.; Benito, G.; Blanco-Rivero, J.; Boscá, L. \& Delgado, C. (2003). Regional distribution of hyperpolarization-activated current $I_{f}$ and hyperpolarization-activated cyclic nucleotide-gated channel mRNA expression in ventricular cells from control and hypertrophied rat hearts. The Journal of Physiology, 553, 395-405, pISSN: 0022-3751.

Heidbuchel, H.; Vereecke, J. \& Carmeliet, E. (1987). The electrophysiological effects of acetylcholine in single human atrial cells. Journal of Molecular and Cellular Cardiology, 19, 1207-1219, pISSN: 0022-2828. 
Hoppe, U.C.; Jansen, E.; Sudkamp, M. \& Beuckelmann, D.J. (1998). Hyperpolarizationactivated inward current in ventricular myocytes from normal and failing human hearts. Circulation, 97, 55-65, pISSN: 0009-7322.

Kaumann, A.J. (1991). 5-HT4-like receptors in mammalian atria. Journal of neural transmission. Supplementum, 34, 195-201.

Lakatta, E.G.; Maltsev, V.A. \& Vinogradova, T.M. (2010). A coupled SYSTEM of intracellular $\mathrm{Ca}^{2+}$ clocks and surface membrane voltage clocks controls the timekeeping mechanism of the heart's pacemaker. Circulation Reseach, 106, 4, 659-73, pISSN: 0009-7330.

Lezoualc'h, F.; Steplewski, K.; Sartiani, L.; Mugelli, A.; Fischmeister, R. \& Bril, A. (2007). Quantitative mRNA analysis of serotonin 5-HT4 receptor isoforms, calcium handling proteins and ion channels in human atrial fibrillation. Biochemical and Biophysical Research Communication, 357, 1, 218-224, pISSN: 0006-291X.

Lonardo, G.; Cerbai, E.; Casini, S.; Giunti, G.; Bonacchi, M.; Battaglia, F.; Fiorani, B.; Stefano P.L.; Sani, G. \& Mugelli, A. (2004). Atrial natriuretic peptide modulates the hyperpolarization-activated current $\left(\mathrm{I}_{\mathrm{f}}\right)$ in human atrial myocytes. Cardiovascular Research, 63, 528-536, pISSN: 0008-6363.

Lonardo, G.; Cerbai, E.; Casini, S.; Giunti, G.; Bonacchi, M.; Battaglia, F.; Fiorani, B.; Stefano, P.L.; Sani, G. \& Mugelli, A. (2004). Atrial natriuretic peptide modulates the hyperpolarization-activated current $\left(\mathrm{I}_{\mathrm{f}}\right)$ in human atrial myocytes. Cardiovascular Research, 63, 528-536, pISSN: 0008-6363.

Ludwig, A.; Zong, X.; Stieber, J.; Hullin, R.; Hofmann, F. \& Biel, M. (1999). Two pacemaker channels from human heart with profoundly different activation kinetics. The EMBO Journal, 18, 9, 2323-2329, pISSN: 0261-4189.

Melchiorre, M.; Del Lungo, M.; Guandalini, L.; Martini, E; Dei, S.; Manetti, D.; Scapecchi, S.; Teodori, E.; Sartiani, L.; Mugelli, A.; Cerbai, E. \& Romanelli, M. N. (2010). Design, synthesis, and preliminary biological evaluation of new isoform-selective f-current blockers. Journal of Medicinal Chemistry, Aug 26 [Epub ahead of print], pISSN: 00222623.

Michels, G.; Er, F.; Khan, I.; Sudkamp, M.; Herzig, S. \& Hoppe, U.C. (2005). Single-channel properties support a potential contribution of hyperpolarization-activated cyclic nucleotide-gated channels and $\mathrm{I}_{\mathrm{f}}$ to cardiac arrhythmias. Circulation, 111, 399-404, pISSN: 0009-7322.

Mommersteeg, M.T.; Hoogaars, W.M.; Prall, O.W.; de Gier-de Vries, C.; Wiese, C.; Clout, D.E.; Papaioannou, V.E.; Brown, N.A.; Harvey, R.P.; Moorman, A.F. \& Christoffels, V.M. (2007). Molecular pathway for the localized formation of the sinoatrial node. Circulation Research, 100, 354-362, pISSN: 0009-7330.

Moosmang, S.; Stieber, J.; Zong, X.; Biel, M.; Hofmann, F. \& Ludwig, A. (2001). Cellular expression and functional characterization of four hyperpolarization-activated pacemaker channels in cardiac and neuronal tissues. European journal of Biochemistry/FEBS, 268, 6, 1646-1652, pISSN: 0014-2956.

Opthof, T. (1998). The membrane current $\left(\mathrm{I}_{\mathrm{f}}\right)$ in human atrial cells: implications for atrial arrhythmias. Cardiovascular Research, 38, 537-540, pISSN: 0008-6363.

Pindon, A.; van Hecke, G.; van Gompel, P.; Lesage, A.S.; Leysen, J.E. \& Jurzak, M. (2002). Differences in signal transduction of two $5-\mathrm{HT}_{4}$ receptor splice variants: compound 
specificity and dual coupling with Galpha s- and Galpha i/o-proteins. Molecular Pharmacology, 61, 85-96, pISSN: 0026-895X.

Pino, R.; Cerbai, E., Calamai, G.; Alajmo, F.; Borgioli, A.; Braconi, L.; Cassai, M.; Montesi, G.F. \& Mugelli, A. (1998). Effect of 5-HT4 receptor stimulation on the pacemaker current If in human isolated atrial myocytes. Cardiovascular Research, 40, 516-522, pISSN: 0008-6363.

Porciatti, F.; Pelzmann, B.; Cerbai, E.; Schaffer, P.; Pino, R.; Bernhart, E.; Koidl , B. \& Mugelli, A. (1997). The pacemaker current $I_{f}$ in single human atrial myocytes and the effect of beta-adrenoceptor and A1-adenosine receptor stimulation. British Journal of Pharmacology, 122, 5, 963-969, pISSN: 0007-1188.

Rao, K.; Fisher, M.L.; Robinson, S.; Shorofsky, S. \& Gottlieb, S. (2007). Effect of chronic changes in heart rate on congestive heart failure. Journal of Cardiac Failure, 13, 4, 269-274, pISSN: 1071-9164.

Robinson, R.B.; Yu, H.; Chang, F. \& Cohen, I.S. (1977). Developmental change in the voltagedependence of the pacemaker current, $\mathrm{I}_{\mathrm{f}}$, in rat ventricle cells. Pflügers Archiv: European Journal of Physiology, 433, 533-535, pISSN: 0031-6768.

Romanelli, M.N.; Cerbai, E.; Dei, S.; Guandalini, L; Martelli, C.; Martini, E.; Scapecchi, S.; Teodori, E. \& Mugelli, A. (2005). Design, synthesis and preliminary biological evaluation of zatebradine analogues as potential blockers of the hyperpolarizationactivated current. Bioorganic \& medicinal chemistry, 13, 4, 1211-1220, pISSN: 09680896.

Sartiani, L.; Stillitano, F.; Luceri, C.; Suffredini, S.; Toti, S.; De Filippo, C.; Cuomo, V.; Tattoli, M.; Dolara, P.; Mugelli, A. \& Cerbai, E. (2010). Prenatal exposure to carbon monoxide delays postnatal cardiac maturation. Laboratory Investigation; a journal of technical methods and pathology, Jul 19 [Epub ahead of print], pISSN: 0023-6837.

Sartiani, L.; Bettiol, E.; Stillitano, F.; Mugelli, A.; Cerbai, E. \& Jaconi, M. E. (2007). Developmental changes in cardiomyocytes differentiated from human embryonic stem cells: a molecular and electrophysiological approach. Stem Cells, 25, 5, 11361144, pISSN: 0250-6793.

Sartiani, L.; De Paoli, P.; Stillitano, F.; Aimond, F.; Vassort, G.; Mugelli, A. \& Cerbai, E. (2006). Functional remodeling in post-myocardial infarcted rats: focus on betaadrenoceptor subtypes. Journal of Molecular and Cellular Cardiology, 40, 2, 258-266, pISSN: 0022-2828.

Schweizer, P.; Yampolsky, P. \& Malik, R. (2009). Transcription profiling of HCN-channel isotypes throughout mouse cardiac development. Basic Research in Cardiology, 104, 621-629, pISSN: 0300-8428.

Stilli, D.; Sgoifo, A.; Macchi, E.; Zaniboni, M.; De Iasio, S.; Cerbai, E.; Mugelli, A.; Lagrasta, C.; Olivetti, G. \& Musso, E. (2001). Myocardial remodeling and arrhythmogenesis in moderate cardiac hypertrophy in rats. American Journal of Physiology. Heart and Circulatory Physiology, 280, 1, H142-H150, pISSN: 0363-6135.

Stillitano, F.; Lonardo, G.; Zicha, S.; Varro, A.; Cerbai, E.; Mugelli, A. \& Nattel S. (2008). Molecular basis of funny current $\left(\mathrm{I}_{\mathrm{f}}\right)$ in normal and failing human heart. Journal of Molecular and Cellular Cardiology, 45, 2, 289-299, pISSN: 0022-2828.

Suffredini, S.; Stillitano, F.; Brogioni, S.; Comini, L.; Ceconi, C.; Sartiani, L.; Bouly, M.; Ferrari, R.; Mugelli, A. \& Cerbai E. (2009). Electrophysiological remodeling in post- 
myocardial infarcted rats: focus on f-current and heart rate. European heart journal supplements: journal of the European Society of Cardiology, 30, 868, abstract, ISSN: 1520$765 X$.

Swedberg, K.; Komajda, M.; Böhm, M.; Borer, J.S.; Ford, I.; Dubost-Brama, A.; Lerebours, G.; Tavazzi, L; SHIFT Investigators. (2010). Ivabradine and outcomes in chronic heart failure (SHIFT): a randomised placebo-controlled study. Lancet, 376 (9744), 875-85, pISSN: 0140-6736.

Swynghedauw, B. (1999). Molecular mechanism of myocardial remodeling. Physiological Reviews, 79, 215-262, pISSN: 0031-9333.

Teerlink, JR. (2010). Ivabradine in heart failure-no paradigm SHIFT *.yet. Lancet, 376 (9744), 847-49, pISSN: 0140-6736.

Thuringer, D.; Lauribe, P. \& Escande, D. (1992). A hyperpolarization-activated inward current in human myocardial cells. Journal of Molecular and Cellular Cardiology, 24, 451-455, pISSN: 0022-2828.

Vassalle, M. (1977). The relationship among cardiac pacemakers. Overdrive suppression. Circulation Research, 41, 269-277, pISSN: 0009-7330.

Vassalle, M. \& Mugelli, A. An oscillatory current in sheep cardiac Purkinje fibers. Circulation Research, 48, 5, 618-631, pISSN: 0009-7330.

Venugopal, J. (2001). Cardiac natriuretic peptides - hope or hype? Journal of Clinical Pharmacy and Therapeutics, 26, 1, 15-31, pISSN: 0269-4727.

Yasui, K.; Liu, W.; Opthof, T.; Kada, K.; Lee, JK.; Kamiya, K. \& Kodama, I. (2001). I(f) current and spontaneous activity in mouse embryonic ventricular myocytes. Circulation Research, 88, 536-542, pISSN: 0009-7330.

Zicha, S.; Fernández-Velasco, M.; Lonardo, G.; L'Heureux, N. \& Nattel, S. (2005). Sinus node dysfunction and hyperpolarization-activated $(\mathrm{HCN})$ channel subunit remodeling in a canine heart failure model. Cardiovascular Research, 66, 3, 472-81, pISSN: 00086363. 


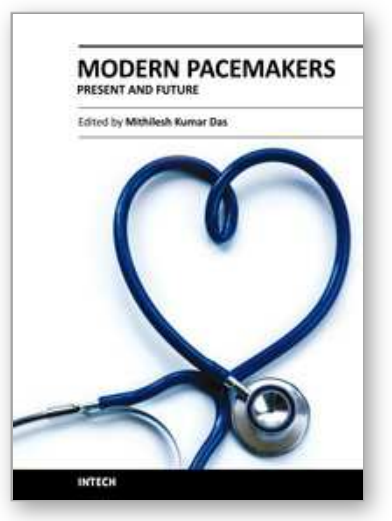

\author{
Modern Pacemakers - Present and Future \\ Edited by Prof. Mithilesh R Das
}

ISBN 978-953-307-214-2

Hard cover, 610 pages

Publisher InTech

Published online 14, February, 2011

Published in print edition February, 2011

The book focuses upon clinical as well as engineering aspects of modern cardiac pacemakers. Modern pacemaker functions, implant techniques, various complications related to implant and complications during follow-up are covered. The issue of interaction between magnetic resonance imaging and pacemakers are well discussed. Chapters are also included discussing the role of pacemakers in congenital and acquired conduction disease. Apart from pacing for bradycardia, the role of pacemakers in cardiac resynchronization therapy has been an important aspect of management of advanced heart failure. The book provides an excellent overview of implantation techniques as well as benefits and limitations of cardiac resynchronization therapy. Pacemaker follow-up with remote monitoring is getting more and more acceptance in clinical practice; therefore, chapters related to various aspects of remote monitoring are also incorporated in the book. The current aspect of cardiac pacemaker physiology and role of cardiac ion channels, as well as the present and future of biopacemakers are included to glimpse into the future management of conductions system diseases. We have also included chapters regarding gut pacemakers as well as pacemaker mechanisms of neural networks. Therefore, the book covers the entire spectrum of modern pacemaker therapy including implant techniques, device related complications, interactions, limitations, and benefits (including the role of pacing role in heart failure), as well as future prospects of cardiac pacing.

\title{
How to reference
}

In order to correctly reference this scholarly work, feel free to copy and paste the following:

Laura Sartiani, Elisabetta Cerbai and Alessandro Mugelli (2011). The Funny Current in Cardiac NonPacemaker Cells: Functional Role and Pharmacological Modulation, Modern Pacemakers - Present and Future, Prof. Mithilesh R Das (Ed.), ISBN: 978-953-307-214-2, InTech, Available from: http://www.intechopen.com/books/modern-pacemakers-present-and-future/the-funny-current-in-cardiac-nonpacemaker-cells-functional-role-and-pharmacological-modulation

\section{INTECH}

open science | open minds

\section{InTech Europe}

University Campus STeP Ri

Slavka Krautzeka 83/A

51000 Rijeka, Croatia

Phone: +385 (51) 770447

\section{InTech China}

Unit 405, Office Block, Hotel Equatorial Shanghai

No.65, Yan An Road (West), Shanghai, 200040, China

中国上海市延安西路65号上海国际贵都大饭店办公楼 405 单元

Phone: +86-21-62489820 
Fax: +385 (51) 686166

Fax: +86-21-62489821

www.intechopen.com 
(C) 2011 The Author(s). Licensee IntechOpen. This chapter is distributed under the terms of the Creative Commons Attribution-NonCommercialShareAlike-3.0 License, which permits use, distribution and reproduction for non-commercial purposes, provided the original is properly cited and derivative works building on this content are distributed under the same license. 